\title{
Patient Engagement: The Fundació ACE Framework for Improving Recruitment and Retention in Alzheimer's Disease
} Research

\author{
Mercè Boada ${ }^{\mathrm{a}, *}$, Miguel A. Santos-Santos ${ }^{\mathrm{a}, \mathrm{b}}$, Octavio Rodríguez-Gómez ${ }^{\mathrm{a}}$, Montserrat Alegret ${ }^{\mathrm{a}}$, \\ Pilar Cañabate ${ }^{\mathrm{a}}$, Asunción Lafuente ${ }^{\mathrm{a}}$, Carla Abdelnour ${ }^{\mathrm{a}}$, Mar Buendía ${ }^{\mathrm{a}}$, Maria José de Dios ${ }^{\mathrm{a}}$, \\ América Morera $^{\mathrm{a}}$, Ángela Sanabria ${ }^{\mathrm{a}}$, Laura Campo ${ }^{\mathrm{c}}$, Agustín Ruiz $^{\mathrm{a}}$ and Lluís Tárraga ${ }^{\mathrm{a}}$ \\ ${ }^{a}$ Research Center and Memory Clinic, Fundació ACE, Institut Català de Neurociències Aplicades, \\ Universitat Internacional de Catalunya, Barcelona, Spain \\ ${ }^{\mathrm{b}}$ Cognition and Brain Plasticity Group, Bellvitge Biomedical Research Institute, IDIBELL, Spain \\ 'International Corporate Affairs, Alzheimer's Disease, Eli Lilly and Co
}

Accepted 11 January 2018

\begin{abstract}
Alzheimer's disease (AD) research is at a critical time. The global society is increasingly aware of the frightening rate of growth of the human and financial burden caused by this condition and of the urgent need to halt its progression. Consequently, the scientific community holds great responsibility to quickly put in place and optimize the machinery necessary for testing new treatments or interventions. In this context demand for participants for AD research is at an all-time high. In this review, we will focus on a methodological factor that is increasingly recognized as a key factor that shapes trial populations and affects validity of results in clinical trials: patient engagement, recruitment, and retention. We outline specific problems relevant to patient engagement in AD including recruiting enough participants, difficulties in participant retention, ensuring the recruited sample is representative of the general AD population, the burden of screening failures, and new challenges related to recruiting in preclinical disease. To address the urgent need for more research studying the applicability and costeffectiveness of different recruitment strategies across different settings and nationalities, we describe the Models of Patient Engagement for Alzheimer's Disease (MOPEAD) project, a public-private partnership promoted by the Innovative Medicine Initiative (IMI), which will provide a large multinational quantitative analysis comparing different innovative recruitment models. We also discuss strategies that address each problem and draw on the experience of Fundació ACE to argue that focusing resources on comprehensive AD centers that offer coordinated clinical and social care and participate in basic and clinical research, is an effective and efficient way of implementing many of the discussed strategies.
\end{abstract}

Keywords: Alzheimer's disease, clinical trials, community outreach, Fundació ACE, MOPEAD, patient engagement, recruitment, retention

\section{INTRODUCTION}

Global Alzheimer's disease (AD) research is at a critical time. $\mathrm{AD}$ is the first cause of dementia

\footnotetext{
${ }^{*}$ Correspondence to: Mercè Boada, Fundació ACE, Gran Via de Carles III, 85 Bis, 08028, Barcelona, Spain. Tel.: +34 934304720;

E-mail: mboada@fundacioace.com.
}

worldwide. The 2015 World Alzheimer Report estimates that the 46.8 million people worldwide living with dementia will almost double every 20 years [1]. The global society is increasingly aware of the frightening rate of growth of the human and financial burden caused by this condition, increasing from 604 billion in 2010 to 818 billion US\$ in 2015, and of the 
urgent need to halt its progression. In the wake of this increased sense of urgency, society is calling for increased action and governments worldwide are responding by recognizing dementia as a public health priority and drafting national plans that increase funding and define strategies to defeat $\mathrm{AD}[2,3]$.

Consequently, the scientific community holds great responsibility to quickly put in place and optimize the machinery necessary for testing new treatments or interventions. Of the many methodological factors that can be improved in AD trials, we will focus on patient engagement, recruitment, and retention. This issue has perhaps garnered less attention than other topics such as study design, establishing effective outcome measures, or incorporating biomarkers but it is increasingly recognized as a key factor that shapes trial populations and affects validity of results $[4,5]$. The demand for participants for $\mathrm{AD}$ research is at an all-time high. Data from the Alzheimer's Association trial match service [6] shows there are more than 250 studies currently looking for volunteers. A recent editorial warns that patient recruitment is the most important rate limiting factor delaying therapy development and is poised to derail the first goal of the National Plan to Address Alzheimer's Disease: to prevent and effectively treat Alzheimer's Disease by 2025 [7]. It describes a meeting in which key stakeholders including the Alzheimer's association, academics, government agencies, and industry outlined an action plan to address this problem. Another recent report from the EU/US task force noted that AD research is faced with unreasonably long periods of recruitment, small proportion of patients recruited per center, and unacceptably high drop-out rates and called for increased research focused on understanding why patients choose or refuse to participate and quantifying the impact of different inclusion criteria and strategies on recruitment [8].

In the following pages, we will outline specific problems relevant to patient engagement in $\mathrm{AD}$ (Table 1) including recruiting enough participants, difficulties in participant retention, ensuring the recruited sample is representative of the general AD population, the burden of screening failures, and new challenges related to recruiting in preclinical disease. We will also discuss strategies (Table 1) that address each problem and draw on the experience of Fundació ACE [9] to argue that focusing resources on comprehensive AD centers that offer coordinated clinical and social care and participate in basic and clinical research, is an effective and efficient way of implementing many of the discussed strategies. Fundació ACE Institut Catala de Neurociences Aplicades, herein after ACE, has developed an integrated multidisciplinary care model in Barcelona (Spain) following the guidelines of the "Catalan Model for Cognitive and Behavioral Disorders in Social Health Care [10]" that includes diagnosis, therapy, followup care, daycare, and a day hospital in the context of an active research program. Since its start in 1996 up to 2016, ACE has performed 21737 diagnoses, evaluated 17642 families, and participated in 128 phase I, II, and III clinical trials.

\section{INCREASING THE NUMBERS OF POTENTIAL PARTICIPANTS}

The first challenge is increasing the pool of potential participants. The demand for participants in $\mathrm{AD}$ research is at an all-time high. Based on data from clinicaltrials.gov, the National Institute on Aging (NIA, USA) counted more than 150 open studies calling for more than 70,000 participants which could require screening of more than 700,000 potential volunteers [11]. Furthermore, the recent trend of focusing efforts in preclinical and prodromal $\mathrm{AD}$ will require more subjects and longer follow-up time to demonstrate treatment effects [12]. Low trial awareness and unfavorable attitudes toward participation are factors that negatively influence recruitment which affect patients, referring doctors, and the society at large. Studies in the US [13] and Europe (IMPACT study, [14]) suggest that the majority of primary care doctors are not aware of AD trials in their area. Patients and families generally depend on their health care providers for information about available clinical studies and doctors who are not specialized in cognitive disorders or aging may understandably not be aware of all the studies recruiting in their area. Reports suggest that willingness to participate depend more on attitudes toward research than caregiver burden [15-17]. Specific concerns regarding the potential harm of treatments and diagnostic tests, the logistical and time consuming burden, or the futility of participation can cause unfavorable attitudes toward participation in patients, care-givers and doctors alike $[14,18-20]$. Primary care physicians also cite lack of time and availability of appropriate diagnostic tools to screen for cognitive impairment as significant barriers to referral to AD studies. These factors probably also contribute to poor detection of cognitive impairment in primary care settings, $20 \%$ 
Table 1

Problems and remedial strategies in patient engagement for AD research

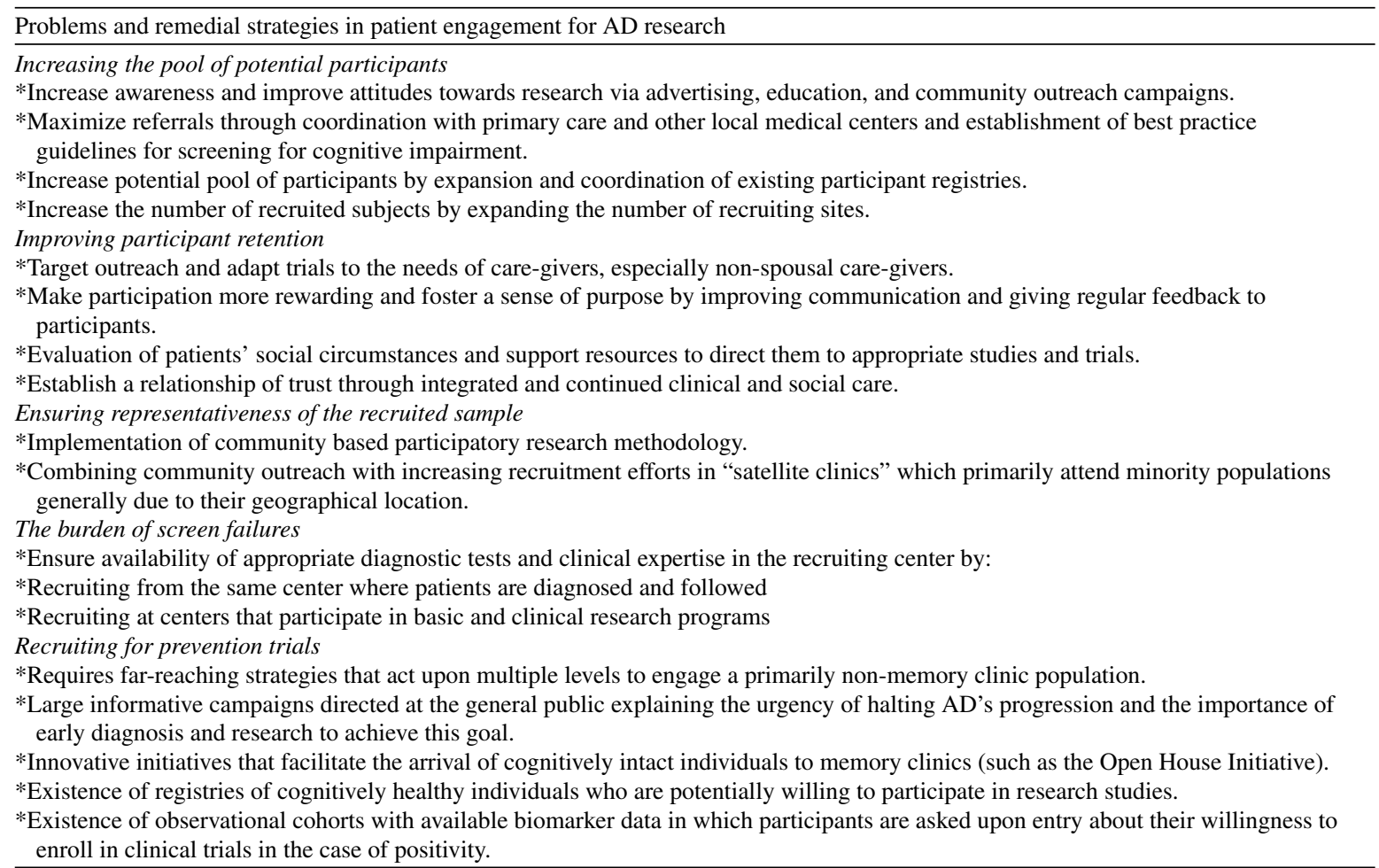

of dementia and $60 \%$ of MCI cases by some reports [21]. Finally, due to a combination of restrictive inclusion criteria (age restrictions, minimum MMSE score, level of education, requirement of a study partner, etc.) and elevated prevalence of comorbidity and poly-pharmacy, a surprisingly small proportion of $\mathrm{AD}$ patients are actually eligible for trials, $27 \%$ and $10-13 \%$ of AD patients from research [22] and clinical $[23,24]$ settings, respectively.

Expanding the number of recruiting sites could be a forthright way of increasing recruitment; however, there is insufficient evidence to direct its implementation. Studies recruiting from multi-national sites face difficulties derived from differences in patient populations, cultural practices, and regulatory agencies [5] and existing research suggests there are significant differences in patient sample characteristics and efficiency depending on the setting (memory clinic versus community [37-39]) or nature (academic versus commercial $[40,41]$ ) of the recruiting center. We need more studies that compare the success and cost-effectiveness of recruiting from different sites including memory clinics, primary care centers, residential homes, and other non-traditional settings such as community centers, or web-based portals. These gaps in knowledge motivated the design of the Models of Patient Engagement for Alzheimer's Disease (MOPEAD) study [42]. Its objective is to understand the obstacles to early diagnosis and treatment faced by $\mathrm{AD}$ patients in various European communities and to develop and evaluate innovative models to overcome them. MOPEAD is a multinational European public-private partnership promoted by the Innovative Medicine Initiative (IMI) and the European Federation of Pharmaceutical Industries and Associations (EFPIA) that will be carried out by 14 partners including academic centers and industry. Four screening models will be tested simultaneously in five European countries to evaluate cost-effectiveness for identifying subjects with early $\mathrm{AD}$ in community settings with different cultural and socioeconomic conditions. The screening models that will be evaluated include online cognitive testing preceded by an online marketing campaign, a memory clinic evaluation preceded by a publicity campaign (Open house model [37]), primary care physician screening based on short cognitive tests and dementia risk score calculation [43], and a similar screening 
procedure undertaken at a specialist outpatient clinic where subjects present elevated risk of dementia: a diabetes clinic in a tertiary care center.

Coordination with primary care and other local medical centers is essential for maximizing referrals. ACE has a contract with the Health Ministry of the Government of Catalonia designating it as a referral center for evaluating cognitive impairment that supports referrals from the districts of greater Barcelona. ACE has received 7,327 new referrals since 2013. Evidence supporting screening for cognitive impairment in the general population is still inadequate [34]; however, publication of best practice guidelines regarding when and how to screen for cognitive impairment or when to refer to the nearest memory clinic could be of great help to primary care and other non-dementia specialists. The professionals at ACE have contributed to best practice guidelines of dementia care [35] and perform teaching activities at primary care centers promoting communication and coordination between centers. The expansion and coordination of existing participant registries has been proposed as a method to increase enrollment [11]. However this remains a challenging task as registries can differ in scale (multinational: European Prevention of Alzheimer's Consortium [EPAD], Global Alzheimer's Platform [GAP]; national: Alzheimer's Prevention Registry, Alzheimer Association's TrialMatch; local institutespecific registries at academic and research centers), model (disease-specific versus general recruitment), and type of data contained (contact information, medical data) and little research is available for guidance [36]. Besides increasing the quantity and speed of recruitment, recently started multinational initiatives such as EPAD and GAP will play a major role in increasing sustainability of AD research. Traditionally, the majority of $\mathrm{AD}$ trials result from the uncoordinated efforts of various private companies and a considerable part of their huge costs can be ascribed to the requirement of having to reconstruct multiple resources for each trial. Costly tasks such as creating registries, establishing the network of sites and individual site preparation, preparing IRB and other administrative documentation, establishing evaluation and data collection protocols, and training personnel are repeated for each trial. The purpose of these initiatives is to build and maintain a structured resource (by coordinating multinational registries) that will allow continued access to patients and to establish a harmonized trial protocol and network of trial ready sites that will improve the logistical burden, cost-efficiency, and comparability of future research.

Education and advertising campaigns could be effective for increasing awareness and improving attitudes toward participation. Some research suggests that investing in community-based education and outreach is more effective than educating primary care providers $[18,25]$ and that direct mailings are more effective than newspaper ads or community outreach [26] but more research is clearly needed comparing effectiveness of targeting different populations (i.e., primary care doctors, residential homes inhabitants and staff, patient support groups, community center members, or the general public) and using different mediums or campaigns including lectures, ground campaigns and pamphlets, and ads in newspapers, radio, television, or internet. Planning and executing these campaigns requires personnel and resources typically available only to large centers. For example, the NIA funded AD Research Centers (ADRC) have education cores in charge of outreach programing. Similarly, ACE counts with an outreach team in charge of maintaining a website and monthly electronic magazine, of interacting with social networks and the media (in 2016 the news generated by ACE reached an estimated audience of more than 60 million people) and organizing community outreach activities (La Nit de l'Alzheimer [27], Regala Memòria [28], Dia Mundial de l'Alzheimer) to raise awareness. The expenses generated by the ACE outreach team account for about $4 \%$ of the total annual expense. Activities such as the Open House Initiative (OHI) [29], offering free cognitive evaluations once a month (452 evaluations in 2016), the Estimul'Art program [30], which organizes visits to art museums for patients and families, diverse teaching and support activities [31], and publication of multiple books and guides $[32,33]$ promoting age-specific $\mathrm{AD}$ education and awareness are based on the principles of "social responsibility" and "giving-first" that foster a relationship of respect and trust with the community.

\section{INCREASING PARTICIPANT RETENTION}

Improving retention of study participants is a challenge of vital importance. Participant drop-out is a key contributor to selection bias which poses a great threat to the internal validity and generalizability of results in clinical trials $[4,5]$. More research analyzing the reasons participants' drop-out of AD trials and evaluating different remedial strategies is urgently 
needed given the long follow-up periods required for trials aimed at preventing progression or development of cognitive impairment in MCI and healthy populations respectively [44]. Analysis of one recent trial in MCI with a $30 \%$ drop-out rate showed that being non-white, not reaching university level education, reporting greater depressive symptoms, having a non-spousal study partner, and recruitment by a commercial non-academic center were associated with higher risk of drop-out [40]. A survey conducted by the Center for Information and Study on Clinical Research Participation [45] suggests that participants who drop-out are more likely to report difficulty understanding the consent form, un-satisfaction with the answers to their questions in the consent form interview, and described the site visits as "stressful." They were also less likely to report self-motivation as the primary reason for participation.

The factors contributing to poor retention and the strategies needed to address them partly overlap with those pertaining to initial recruitment. In particular, increasing outreach, education, or advertisements targeting health care providers, patients, caregivers, and the general public could help improve poor motivation and unfavorable attitudes towards research that affect recruitment and retention alike. Targeting outreach and adapting trials to the needs of care-givers, especially non-spousal care-givers, seems especially important given that participants with non-spousal study partners are less willing to participate [15] and twice as likely to drop-out [40]. One study suggests that reducing travel inconveniences, increasing the probability of assignment to a treatment group, and educating about the risks of participation could increase care-givers willingness to participate [16]. Contrary to what some may expect, a recent review reports that disease severity, trial length, or placebo group placement did not clearly affect drop-out rate [5] suggesting that other factors affecting participants' subjective experience such as the quality of care and the information received or the sense of purpose, of being part of a larger enterprise, are more important determinants of study completion. The finding that subjects recruited by commercial centers are twice as likely to drop-out also supports this idea [40]. Interviews of AD research participants show they value the access to diagnosis, care, emotional support and up-to-date information about new treatments [17] that come with participation in clinical research. It follows that improving communication and establishing a relationship of trust with patients and care-givers is paramount to increase adherence.
Offering regular feedback via written reports or personal meetings and organizing periodic research participant gatherings are examples of activities that could be implemented. Offering continued care, from both clinical and social perspectives, instead of discontinuing visits in advanced stages of disease or at the end of a trial is essential for participants to feel supported instead of utilized. Furthermore, knowledge of patients' social circumstances and support resources can help direct them to appropriate studies and trials increasing the probability of study completion. Patients and families seek out and trust in ACE because of this type of integrated care. At first visit, every patient receives a clinical and social evaluation. Follow-up medical (18,545 visits since 2013) and social care $(9,898$ families evaluated and followed up between 2006-2015) [46] is also always offered and many patients $(5,291$ since 1991$)$ participate in day care and cognitive [47] stimulation programs.

\section{ENSURING REPRESENTATIVENESS OF THE RECRUITED SAMPLE}

The recruited sample should be representative of the general population presenting the studied condition to ensure external validity and generalizability of trial results. However, this is usually not the case in $\mathrm{AD}$ trials [24]. One of the main reasons is that many trials exclude subjects with significant comorbidities or taking multiple medications making the majority of $\mathrm{AD}$ patients followed in clinics ineligible for trials $[23,24]$. In our experience, around $10 \%$ of patients diagnosed with $\mathrm{AD}$ at ACE are eligible for trials and the main reasons for exclusion are advanced severity of disease, comorbidities, polypharmacy, and absence of a study partner. It is also well documented that research participants tend to be of higher educational and socioeconomic levels than the general population [48]. There are probably multiple interrelated causes of this phenomenon including increased health awareness and confidence in science and research institutions in individuals of higher sociocultural levels. With respect to $\mathrm{AD}$ research in particular, differences in conceptualization and attitude towards the disease across different social groups may also be a relevant factor [46]. It is noteworthy that ethnic and racial minorities are systematically underrepresented in clinical trials and observational studies. A 2007 review showed that in the US only $3.2 \%$ of the subjects included in clinical trials promoted by industry were non- 
white [49]. Possible causes are distrust toward the medical establishment and research institutions, barriers to access medical services, language barriers, logistic and financial burden, lack of similarity and cultural empathy between researchers and potential participants $[11,50]$. This over representation of white participants supposes a dangerous bias for AD research, especially since there is evidence showing that minority groups could have increased risk of presenting $\mathrm{AD}$ [51] and the US Census Bureau estimates non-Hispanic whites will make up less than half of the population by the year 2044 [52].

Different strategies have been proposed and tested with the objective of recruiting representative samples for clinical trials and increasing research participation in racial and ethnic minorities. Community outreach is a useful strategy in which direct contact is established with a specific community via alliances with its leaders or representative associations. Inviting community leaders and members to lectures or informative seminars regarding disease management and research opportunities are usual practices. The concept of community based participatory research (CBPR) defines a structured and bidirectional methodology of community outreach that endeavors to reduce the distance between researchers and a community by establishing a forum of mutual communication and learning [53]. Investigators inform of research results with the objective of causing a positive impact in the health of the community and so its members understand the importance of scientific research and the principles it is based on. Likewise, researchers receive feed-back from community members regarding their preferences and opinions as potential participants, allowing them to adapt research methodology to "real world" community needs. In this manner the community becomes an active player in the research process and a relationship of mutual trust is generated $[54,55]$. Instead of attributing the absence of individuals from a specific community to their distrust of scientific and medical institutions, this methodology helps scientists take an active role in studying the role of the scientific community in creating and reducing this distrust. CBPR methods have been used successfully for recruiting minorities in $\mathrm{AD}$ research [56, 57]. For its success, it is necessary that researchers establishing contact understand specific aspects about the culture of the community and maintain direct and stable contact which typically requires research centers to designate personnel and resources specifically to outreach activities. Promoting the "retooling" of staff scien- tists to learn how to build community partnerships could be an effective strategy for success of community outreach activities. Another strategy that has also proved useful when combined with community outreach methods [58, 59] involves concentrating recruitment efforts on "satellite clinics" which primarily attend minority populations generally due to their geographical location.

\section{THE BURDEN OF SCREEN FAILURES}

Screening accuracy has profound effects on the number of participants required and the cost and length of recruitment. A failure in screening in $\mathrm{AD}$ trials generally denotes a participant who does not meet the inclusion/exclusion criteria after undergoing lengthy (possibly $>10 \mathrm{~h}$ ) and expensive (>8000 US\$ per subject) procedures including clinical and cognitive evaluations, blood and CSF analysis, and MRI and PET brain scans. Screen failure rate has been worryingly high in AD trials and inclusion of subjects without $\mathrm{AD}$ is often cited as one of the main reasons of failed trials in the past [60]. The introduction of $\mathrm{AD}$ biomarker inclusion criteria has helped identify subjects with putative AD; however, it has introduced the new problem of predicting which subjects will be amyloid PET or CSF positive and screen failure rate has sky rocketed to $70-90 \%$ in recent trials of prodromal $\mathrm{AD}$ (MCI with positive $\mathrm{AD}$ biomarkers) [61]. The younger age of participants in prevention trials comes with lower prevalence of some causes of screen failure such as co-morbidity and poly-pharmacy however the probability of biomarker positivity indicating brain amyloidosis is also lower making the reduction of screen failure rate an even greater challenge in trials of preclinical AD (cognitively intact subjects with positive AD biomarkers).

Improving screening accuracy starts early in the trial design phase. The selection of inclusion/exclusion criteria requires substantial prior knowledge and planning to identify a target population which is feasible to recruit with the available resources. The ability to perform accurate and reliable clinical diagnoses is also essential to reduce screen failures and crucially depends on the availability of appropriate diagnostic tests and clinical expertise in the recruiting center. Recruiting from the same center where patients are diagnosed and followed entails that the same team of expert clinicians is involved or at least in frequent and close communication with the professionals in charge of recruiting. 
Active participation in basic and clinical research programs and longitudinal studies adds further expertise that benefits screening accuracy. The use of sample enrichment and targeted clinical trial designs hold great potential for reducing recruitment requirements by increasing the power of finding treatment effects in heterogeneous conditions such as $\operatorname{AD}[12,62]$. These techniques are based on the idea that the treatment under study might benefit a subset of patients in the population in particular [63]. In AD trials this may entail enriching a MCI sample with subjects that are likely to show early significant decline or randomizing only subjects with positive brain amyloidosis biomarkers to receive an anti-amyloid medication. Since these techniques rely critically on the challenging task of reliably identifying a subset of patients, errors in implementation can result in elevated rates of screening failure. This is yet another reason that supports concentrating recruitment activity in comprehensive $A D$ centers that run basic and clinical research programs besides offering diagnosis and continued care. For example, by developing its own neuropsychological battery and normative data that allow calculation of sensitivity and specificity for detecting dementia [64], ACE is able to identify a subset of MCI in which $70 \%$ of subjects convert to dementia in less than 2 years [65]. Similarly, active genetic [66], CSF biomarker, neuroimaging [67, 68], and longitudinal aging [69] research programs provide the tools and knowledge of how to classify patients according to genetic, CSF, neuroimaging, and clinical features and contribute to the low screen failure rate at ACE (72 out of 384 patients, 19\%, in 2016).

\section{IMPLICATIONS OF RECRUITING FOR PREVENTION TRIALS}

Preventive clinical trials are gaining importance as the scientific community realizes it may be necessary to intervene at earlier stages of $\mathrm{AD}$ for treatments to be effective [70]. Different levels of prevention have been defined in the context of the establishment of preclinical AD as a nosologic entity [71]. Primary prevention targets healthy subjects with the objective of preventing the biologic processes associated with the disease whereas secondary prevention is directed at cognitively intact subjects that present preclinical $\mathrm{AD}$ [72], which refers to biologic evidence of $\mathrm{AD}$ in the form of deterministic genes or positive biomarkers. Primary and secondary prevention trials present many common features but there are also important differences that can affect recruitment.

A common feature is that the target population of preventive trials is generally not found in the usual clinical settings. Cognitively intact individuals typically make up only a small proportion of the population attended by memory clinics. These individuals are generally younger than those with MCI or dementia and are usually active members of the workforce with little availability for multiple visits and medical procedures. Another common feature is that the probability of short term cognitive decline is lower in this population requiring an elevated number of participants or longer follow-up periods to ensure enough power to detect statistically significant treatment effects [73]. Sample size and trial length are especially large in primary prevention trials $[74,75]$ because, in the absence of biologic evidence of $\mathrm{AD}$, the expected rate of progression is similar to that of the general population. In this case, an often employed strategy is "enrichment" of the sample with AD risk factors such as older age [76], APOE carriers [77], or other modifiable risk factors [78]. Though the expected rate of progression is faster, secondary prevention trials present their own significant logistic and ethical challenges [79]. In this case, cognitively intact individuals are told they have an increased risk of developing cognitive impairment and dementia (possibly without a clear time-frame) and are offered to participate in a complex trial consisting of multiple time-consuming visits, medical procedures which are not always innocuous, and exposure to an experimental treatment. All of these circumstances complicate the recruitment process. In our experience at ACE, the time necessary for informed consent is significantly longer and the proportion of individuals who decline trial participation is much higher than in $\mathrm{MCI}$ or $\mathrm{AD}$ trials. Adding positive biomarkers to inclusion criteria also complicates recruitment. Biomarker analysis is not part of the typical work up in cognitively intact subjects and predicting a positive result based on clinical evaluation is very challenging which can lead to high screen failure rate due to biomarker negativity [36].

These difficulties related to recruiting for AD prevention trials necessitate far-reaching strategies that act upon multiple levels to engage a primarily nonmemory clinic population [73]. Large informative campaigns directed at the general public explaining the urgency of halting AD's epidemic progression and of the importance of research to succeed in this enormous challenge. The global society needs to 
understand that dementia and $\mathrm{AD}$ are partially preventable by intervening upon modifiable risk factors and that these conditions begin with a long preclinical stage in which interventions are potentially more effective. In this manner it is foreseeable that the number of asymptomatic people who decide to undergo a "cognitive check-up" and enroll in research programs will grow.

Memory clinics can implement certain initiatives with the objective of facilitating the arrival of cognitively intact individuals. Since 2008, ACE carries out an Open House Initiative (OHI) as part of its corporate social responsibility program in which a local publicity campaign invites anybody over the age of 50 to come to the memory clinic for a "cognitive checkup" free of charge and without the requirement of being referred by another medical professional [37]. Subjects meeting inclusion criteria for any ongoing research studies are invited to participate on a later date. Since its start, the OHI has attracted almost two-thousand (approximately 300 in 2016) cognitively intact individuals which would probably not have come to the memory clinic otherwise and many of these individuals have enrolled in clinical trials or observational studies [69]. On average, each evaluation includes 40 minutes of a neurologist or neuropsychologist's time for performing the cognitive evaluation, 20 minutes of administrative paperwork, and 15 minutes of nurse-time. It is of note that the setting and mode of recruitment can affect sample characteristics. There is evidence showing that cognitively intact subjects recruited from memory clinics show higher rates of AD biomarker positivity than those recruited from the community $[39,80]$. Thus recruiting from non-memory clinic settings gives access to a larger pool of potential participants but may result in lower prevalence of positive $\mathrm{AD}$ biomarkers and higher rates of screen failure [37].

Registries of cognitively healthy individuals who are potentially willing to participate in research studies could be a valid source of participants for preventive clinical trials. Proper coordination between multiple registries and a network of centers that are geographically close to potential participants and offer the possibility of participation is necessary to maximize efficiency of this strategy [55]. However, in the case of secondary prevention trials that require positive biomarkers, most subjects in the registry would probably not be eligible and many may not accept enrollment into a trial of an experimental drug. In this case, an intermediate option that could facili- tate recruitment of individuals with preclinical AD is the existence of observational cohorts with available biomarker data in which participants are asked upon entry about their willingness to enroll in clinical trials in the case of biomarker positivity and the consequent increased risk of developing cognitive impairment [81].

\section{CONCLUSION}

The goal of this article was to highlight the critical role of patient engagement in the challenge of developing treatment and prevention strategies for AD. We outlined specific problems and discussed various remedial strategies that can be implemented by comprehensive AD centers. To increase the pool of potential participants we considered the possibility of expansion of recruiting sites, coordination of participant registries, coordination with primary care and other local medical centers, and increasing awareness and improving the general public's attitude towards participation in research through advertisement and outreach. Targeting outreach and adapting trials to the needs of caregivers, improving communication and offering regular feedback, and building a relationship of trust through continued clinical and social care could improve participant retention in trials and longitudinal studies. Implementation of community based participatory research methodology could help improve diversity and representativeness of the recruited sample with respect to "real-world" $A D$ patients in the population. Focusing recruitment in the same centers that diagnose and follow patients and that participate in research helps guarantee availability of the clinical expertise and technical resources that are necessary to reduce screening failure rate. Finally, specific challenges relating to recruitment in the preclinical AD population were discussed.

Recruitment and retention is increasingly recognized as one of the most important rate limiting factors delaying therapy development and key stakeholders in $\mathrm{AD}$ research world-wide are designing work groups and action plans to address this urgent difficulty. We provided an overview of specific difficulties related to patient recruitment and retention and strategies to address these problems drawing from our experience at ACE. There is an urgent need for research studying the applicability and cost-effectiveness of different recruitment strategies across different settings and nationalities. In this line, we described the Models of Patient Engagement for 
Alzheimer's Disease (MOPEAD) project which will provide a large multinational quantitative analysis comparing different innovative recruitment models. The specific methods and organization of ACE are likely not generalizable to all parts the world, however the success of ACE shows that a model of integrated clinical and social patient-centered care with a builtin research emphasis and an active outreach team can effectively implement strategies that increase patient engagement in the local community.

\section{DISCLOSURE STATEMENT}

Authors' disclosures available online (https:// www.j-alz.com/manuscript-disclosures/17-0866r1).

\section{REFERENCES}

[1] Alzheimer's Disease International (2015) World Alzheimer Report 2015. London, UK.

[2] National Plan to Address Alzheimer's Disease: 2016 Update | ASPE. Available at: https://aspe.hhs.gov/report/nationalplan-address-alzheimers-disease-2016-update. Accessed 2017-08-30.

[3] National Dementia Strategies - Policy in Practice Alzheimer Europe. Available at: http://www.alzheimereurope.org/Policy-in-Practice2/National-DementiaStrategies. Accessed 2017-08-30.

[4] Coley N, Andrieu S, Gardette V, Gillette-Guyonnet S, Sanz C, Vellas B, Grand A (2008) Dementia prevention: Methodological explanations for inconsistent results. Epidemiol Rev 30, 35-66.

[5] Grill JD, Karlawish J (2010) Addressing the challenges to successful recruitment and retention in Alzheimer's disease clinical trials. Alzheimers Res Ther 2, 34.

[6] Clinical Trials and Studies - Myths vs. Facts | Research Center | Alzheimer's Association. Available at: http://www.alz.org/research/clinical_trials/myth_vs_fact.asp. Accessed 2017-08-30.

[7] Fargo KN, Carrillo MC, Weiner MW, Potter WZ, Khachaturian Z (2016) The crisis in recruitment for clinical trials in Alzheimer's and dementia: An action plan for solutions. Alzheimers Dement 12, 1113-1115.

[8] Vellas B, Hampel H, Rouge-Bugat ME, Grundman M, Andrieu S, Abu-Shakra S, Bateman R, Berman R, Black R, Carrillo M, Donohue M, Mintun M, Morris J, Petersen R, Thomas RG, Suhy J, Schneider L, Seely L, Tariot P, Touchon J, Weiner M, Sampaio C, Aisen P (2012) Alzheimer's disease therapeutic trials: EU/US Task Force report on recruitment, retention, and methodology. $J$ Nutr Health Aging 16, 339-345.

[9] Boada M, Tarraga L, Hernandez I, Valero S, Alegret M, Ruiz A, Lopez OL, Becker JT (2014) Design of a comprehensive Alzheimer's disease clinic and research center in Spain to meet critical patient and family needs. Alzheimers Dement 10, 409-415.

[10] Boada M (1996) Catalan model for cognitive and behavioral disorders in social health care. In Pla de Salut, Departament de Sanitat. Generalitat de Catalunya.
[11] Watson JL, Ryan L, Silverberg N, Cahan V, Bernard MA (2014) Obstacles and opportunities in Alzheimer's clinical trial recruitment. Health Aff (Millwood) 33, 574-579.

[12] Pillai JA, Cummings JL (2013) Clinical trials in predementia stages of Alzheimer disease. Med Clin North Am 97, 439457.

[13] Moore P. Alzheimer's Association Clinical Studies Initiative Recruitment and Retention Challenges and Opportunities For the Alzheimer Disease Centers. Available at: https:// www.alz.washington.edu/NONMEMBER/FALL07/moore. pdf. Accessed 2017-08-31.

[14] Jones RW, Andrieu S, Knox S, Mackell J (2010) Physicians and caregivers: Ready and waiting for increased participation in clinical research. $J$ Nutr Health Aging 14, 563-568.

[15] Cary MS, Rubright JD, Grill JD, Karlawish J (2015) Why are spousal caregivers more prevalent than nonspousal caregivers as study partners in AD dementia clinical trials? Alzheimer Dis Assoc Disord 29, 70-74.

[16] Karlawish J, Cary MS, Rubright J, Tenhave T (2008) How redesigning AD clinical trials might increase study partners' willingness to participate. Neurology 71, 1883-1888.

[17] Connell CM, Shaw BA, Holmes SB, Foster NL (2001) Caregivers' attitudes toward their family members' participation in Alzheimer disease research: Implications for recruitment and retention. Alzheimer Dis Assoc Disord 15, 137-145.

[18] Carr SA, Davis R, Spencer D, Smart M, Hudson J, Freeman S, Cooper GE, Schmitt FA, Markesbery WR, Danner D, Jicha GA (2010) Comparison of recruitment efforts targeted at primary care physicians versus the community at large for participation in Alzheimer disease clinical trials. Alzheimer Dis Assoc Disord 24, 165-170.

[19] Lahjibi-Paulet H, Dauffy Alain A, Minard A, Gaxatte C, Saint-Jean O, Somme D (2012) Attitudes toward Alzheimer's disease: A qualitative study of the role played by social representation on a convenient sample of French general practitioners. Aging Clin Exp Res 24, 384-390.

[20] Galvin JE, Meuser TM, Boise L, Connell CM (2009) Predictors of physician referral for patient recruitment to Alzheimer disease clinical trials. Alzheimer Dis Assoc Disord 23, 352-356.

[21] Chodosh J, Petitti DB, Elliott M, Hays RD, Crooks VC, Reuben DB, Galen Buckwalter J, Wenger N (2004) Physician recognition of cognitive impairment: Evaluating the need for improvement. J Am Geriatr Soc 52, 1051-1059.

[22] Grill JD, Monsell S, Karlawish J (2012) Are patients whose study partners are spouses more likely to be eligible for Alzheimer's disease clinical trials? Dement Geriatr Cogn Disord 33, 334-340.

[23] Treves TA, Verchovsky R, Klimovitsky S, Korczyn AD (2000) Recruitment rate to drug trials for dementia of the Alzheimer type. Alzheimer Dis Assoc Disord 14, 209-211.

[24] Schneider LS, Olin JT, Lyness SA, Chui HC (1997) Eligibility of Alzheimer's disease clinic patients for clinical trials. J Am Geriatr Soc 45, 923-928.

[25] Etkin CD, Farran CJ, Barnes LL, Shah RC (2012) Recruitment and enrollment of caregivers for a lifestyle physical activity clinical trial. Res Nurs Health 35, 70-81.

[26] Morrison K, Winter L, Gitlin LN (2016) Recruiting community-based dementia patients and caregivers in a nonpharmacologic randomized trial: What works and how much does it cost? J Appl Gerontol 35, 788-800.

[27] La Noche del Alzheimer: Una noche para la investigación. Available at: http://www.fundacioace.com/la-noche-delalzheimer. Accessed 2017-08-30. 
[28] Regala memoria premiada como mejor campaña de marketing social. Available at: http://www.fundacioace.com/ regala-memoria-premiada/. Accessed 2017-08-30.

[29] jpo - Fundació ACE. Available at: http://www.fun dacioace.com/rsc-jpo/\#1450945947555-f3eb356d-3760. Accessed 2017-08-30.

[30] Estimul'Art - Fundació ACE. Available at: http://www. fundacioace.com/rsc-estimulart/. Accessed 2017-08-30.

[31] Grupos de apoyo a familiares y cuidadores - Unidad de Diagnóstico. Available at: http://www.fundacioace. com/recursos-grupos-de-apoyo/. Accessed 2017-08-30.

[32] Blasco A, Sanchez I, del Barrio M (2016) Tú, yo y el Alzheimer, Sanidad y Ediciones, S.L.

[33] Programa escolar - Fundació ACE. Available at: http:// www.fundacioace.com/wp-content/uploads/2015/12/ Tú-yo-y-el-Alzheimer-cómic.pdf. Accessed 2017-08-30.

[34] Final Recommendation Statement: Cognitive Impairment in Older Adults: Screening - US Preventive Services Task Force. Available at: https://www.uspreventive servicestaskforce.org/Page/Document/RecommendationSt atementFinal/cognitive-impairment-in-older-adultsscreening. Accessed 2017-08-30.

[35] Grupo de trabajo de la Guía de Práctica Clínica sobre la atención integral a las personas con enfermedad de Alzheimer, y otras demencias (2010) Guía de Práctica Clínica sobre la Atención Integral a las Personas con Enfermedad de Alzheimer y otras Demencias. Available at: http:// www.guiasalud.es/GPC/GPC_484_Alzheimer_AIAQS_com pl.pdf. Accessed 2017-08-30.

[36] Grill JD (2017) Recruiting to preclinical Alzheimer's disease clinical trials through registries. Alzheimers Dement ( $N$ Y) 3, 205-212.

[37] Rodriguez-Gomez O, Abdelnour C, Jessen F, Valero S, Boada M (2015) Influence of sampling and recruitment methods in studies of subjective cognitive decline. J Alzheimers Dis 48(Suppl 1), S99-S107.

[38] Abdelnour C, Rodriguez-Gomez O, Alegret M, Valero S, Moreno-Grau S, Sanabria A, Hernandez I, RosendeRoca M, Vargas L, Mauleon A, Sanchez D, Espinosa A, Ortega G, Perez-Cordon A, Diego S, Gailhajanet A, Guitart M, Sotolongo-Grau O, Ruiz A, Tarraga L, Boada M (2017) Impact of recruitment methods in subjective cognitive decline. J Alzheimers Dis 57, 625-632.

[39] Perrotin A, La Joie R, de La Sayette V, Barre L, Mezenge F, Mutlu J, Guilloteau D, Egret S, Eustache F, Chetelat G (2017) Subjective cognitive decline in cognitively normal elders from the community or from a memory clinic: Differential affective and imaging correlates. Alzheimers Dement 13, 550-560.

[40] Edland SD, Emond JA, Aisen PS, Petersen RC (2010) NIA-funded Alzheimer centers are more efficient than commercial clinical recruitment sites for conducting secondary prevention trials of dementia. Alzheimer Dis Assoc Disord 24, 159-164.

[41] Petersen RC, Thomas RG, Aisen PS, Mohs RC, Carrillo MC, Albert MS (2017) Randomized controlled trials in mild cognitive impairment: Sources of variability. Neurology $\mathbf{8 8}$, 1751-1758.

[42] MOPEAD|IMI - Innovative Medicines Initiative. Available at: https://www.imi.europa.eu/content/mopead. Accessed 2017-08-30

[43] Exalto LG, Quesenberry CP, Barnes D, Kivipelto M, Biessels GJ, Whitmer RA (2014) Midlife risk score for the prediction of dementia four decades later. Alzheimers Dement 10, 562-570.
[44] Andrieu S, Coley N, Gardette V, Subra J, Oustric S, Fournier T, Poulain J-P, Coniasse-Brioude D, Igier V, Vellas B, Grand A (2012) Representations and practices of prevention in elderly populations: Investigating acceptance to participate in and adhesion to an intervention study for the prevention of Alzheimer's disease (ACCEPT study)-the need for a multidisciplinary approach. $J$ Nutr Health Aging 16, 352-354.

[45] The Center for Information and Study on Clinical Research Participation (2016) 2013 CISCRP Perceptions and Insights Study: Ineligible Participants and Those Who Terminate Participation Early.

[46] Canabate P, Martinez G, Rosende-Roca M, Moreno M, Preckler S, Valero S, Sotolongo O, Hernandez I, Alegret M, Ortega G, Espinosa A, Mauleon A, Vargas L, Rodriguez O, Abdelnour C, Sanchez D, Martin E, Ruiz A, Tarraga L, Boada M (2017) Social representation of dementia: An analysis of 5,792 consecutive cases evaluated in a memory clinic. J Alzheimers Dis 58, 1099-1108.

[47] Ibarria M, Alegret M, Valero S, Morera A, Guitart M, Canabate P, Moreno M, Lara S, Diego S, Hernandez J, Tantinya N, Vera M, Hernandez I, Becker JT, Ruiz A, Boada M, Tarraga L (2016) Beneficial effects of an integrated psychostimulation program in patients with Alzheimer's disease. $J$ Alzheimers Dis 50, 559-566.

[48] Brodaty H, Mothakunnel A, de Vel-Palumbo M, Ames D, Ellis KA, Reppermund S, Kochan NA, Savage G, Trollor JN, Crawford J, Sachdev PS (2014) Influence of population versus convenience sampling on sample characteristics in studies of cognitive aging. Ann Epidemiol 24, 63-71.

[49] Faison WE, Schultz SK, Aerssens J, Alvidrez J, Anand R, Farrer LA, Jarvik L, Manly J, McRae T, Murphy GMJ, Olin JT, Regier D, Sano M, Mintzer JE (2007) Potential ethnic modifiers in the assessment and treatment of Alzheimer's disease: Challenges for the future. Int Psychogeriatrics 19, 539-558.

[50] Dilworth-Anderson P (2011) Introduction to the science of recruitment and retention among ethnically diverse populations. Gerontologist 51(Suppl 1), S1-S4.

[51] Tang MX, Cross P, Andrews H, Jacobs DM, Small S, Bell K, Merchant C, Lantigua R, Costa R, Stern Y, Mayeux R (2001) Incidence of $\mathrm{AD}$ in African-Americans, Caribbean Hispanics, and Caucasians in northern Manhattan. Neurology 56, 49-56.

[52] Colby SL, Ortman JM (2015) Projections of the size and composition of the US population: 2014 to 2060. Curr Popul Reports, P25-1143.

[53] Schulz AJ, Israel BA, Lantz P (2003) Instrument for evaluating dimensions of group dynamics within community-based participatory research partnerships. Eval Program Plann 26, 249-262.

[54] Israel BA, Schulz AJ, Parker EA, Becker AB (1998) Review of community-based research: Assessing partnership approaches to improve public health. Anпи Rev Public Health 19, 173-202.

[55] Grill JD, Galvin JE (2014) Facilitating Alzheimer disease research recruitment. Alzheimer Dis Assoc Disord 28, 1-8.

[56] Morhardt D, Pereyra M, Iris M (2010) Seeking a diagnosis for memory problems: The experiences of caregivers and families in 5 limited English proficiency communities. Alzheimer Dis Assoc Disord 24 Suppl, S42-S48.

[57] O'Bryant SE, Johnson L, Balldin V, Edwards M, Barber R, Williams B, Devous M, Cushings B, Knebl J, Hall J (2013) Characterization of Mexican Americans with mild cognitive impairment and Alzheimer's disease. J Alzheimers Dis $\mathbf{3 3}$ 373-379. 
[58] Bachman DL, Stuckey M, Ebeling M, Wagner MT, Evans WJ, Hirth V, Walker A, Memon M, Joglekar R, Faison W, Mintzer JE (2009) Establishment of a predominantly African-American cohort for the study of Alzheimer's disease: The South Carolina Alzheimer's disease clinical core. Dement Geriatr Cogn Disord 27, 329-336.

[59] Williams MM, Meisel MM, Williams J, Morris JC (2011) An interdisciplinary outreach model of African American recruitment for Alzheimer's disease research. Gerontologist 51(Suppl 1), S134-S141.

[60] Cummings J (2017) Lessons learned from Alzheimer disease: Clinical trials with negative outcomes. Clin Transl Sci. doi: $10.1111 /$ cts. 12491

[61] Improving Screen Failure And Recruitment Rates In Alzheimer's Disease Clinical Trials - Worldwide Clinical Trials, Last updated 2016, Accessed on 2016. Available at: https://www.worldwide.com/blog/2016/10/improvingscreen-failure-recruitment-rates-alzheimers-diseaseclinical-trials/. Accessed 2017-08-30.

[62] Vellas B, Carrillo MC, Sampaio C, Brashear HR, Siemers E, Hampel H, Schneider LS, Weiner M, Doody R, Khachaturian Z, Cedarbaum J, Grundman M, Broich K, Giacobini E, Dubois B, Sperling R, Wilcock GK, Fox N, Scheltens P, Touchon J, Hendrix S, Andrieu S, Aisen P (2013) Designing drug trials for Alzheimer's disease: What we have learned from the release of the phase III antibody trials: A report from the EU/US/CTAD Task Force. Alzheimers Dement 9 , 438-444.

[63] George SL, Wang X (2012) Targeted clinical trials. In Designs for Clinical Trials: Perspectives on Current Issues, Harrington D, ed. Springer New York, New York, NY, pp. 157-177.

[64] Alegret M, Espinosa A, Valero S, Vinyes-Junque G, Ruiz A, Hernandez I, Rosende-Roca M, Mauleon A, Becker JT, Tarraga L, Boada M (2013) Cut-off scores of a brief neuropsychological battery (NBACE) for Spanish individual adults older than 44 years old. PLoS One 8, e76436.

[65] Espinosa A, Alegret M, Valero S, Vinyes-Junque G, Hernandez I, Mauleon A, Rosende-Roca M, Ruiz A, Lopez O, Tarraga L, Boada M (2013) A longitudinal follow-up of 550 mild cognitive impairment patients: Evidence for large conversion to dementia rates and detection of major risk factors involved. J Alzheimers Dis 34, 769-780.

[66] Ruiz A, Hernandez I, Ronsende-Roca M, Gonzalez-Perez A, Rodriguez-Noriega E, Ramirez-Lorca R, Mauleon A, Moreno-Rey C, Boswell L, Tune L, Valero S, Alegret M, Gayan J, Becker JT, Real LM, Tarraga L, Ballard C, Terrin M, Sherman S, Payami H, Lopez OL, Mintzer JE, Boada M (2013) Exploratory analysis of seven Alzheimer's disease genes: Disease progression. Neurobiol Aging 34, 1310.e1-7.

[67] Espinosa A, Alegret M, Pesini P, Valero S, Lafuente A, Buendia M, San Jose I, Ibarria M, Tejero MA, Gimenez J, Ruiz S, Hernandez I, Pujadas F, Martinez-Lage P, Munuera J, Arbizu J, Tarraga L, Hendrix SB, Ruiz A, Becker JT, Landau SM, Sotolongo-Grau O, Sarasa M, Boada M (2017) Cognitive composites domain scores related to neuroimaging biomarkers within probable-amnestic mild cognitive impairment-storage subtype. J Alzheimers Dis 57, 447-459.

[68] Alegret M, Cuberas-Borros G, Espinosa A, Valero S, Hernandez I, Ruiz A, Becker JT, Rosende-Roca M, Mauleon A, Sotolongo O, Castell-Conesa J, Roca I, Tarraga L, Boada M (2014) Cognitive, genetic, and brain perfusion factors associated with four year incidence of Alzheimer's disease from mild cognitive impairment. J Alzheimers Dis $\mathbf{4 1}$, 739-748.
[69] Rodriguez-Gomez O, Sanabria A, Perez-Cordon A, Sanchez-Ruiz D, Abdelnour C, Valero S, Hernandez I, Rosende-Roca M, Mauleon A, Vargas L, Alegret M, Espinosa A, Ortega G, Guitart M, Gailhajanet A, SotolongoGrau O, Moreno-Grau S, Ruiz S, Tarragona M, Serra J, Martin E, Peleja E, Lomeña F, Campos F, Vivas A, GomezChiari M, Tejero MA, Giménez J, Pesini P, Sarasa M, Martinez G, Ruiz A, Tarraga L, Boada M, RodriguezGomez O (2016) FACEHBI: A prospective study of risk factors, biomarkers and cognition in a cohort of individuals with subjective cognitive decline. Study rationale and research protocols. J Prev Alzheimers Dis 4, 100-108.

[70] Sperling RA, Jack CRJ, Aisen PS (2011) Testing the right target and right drug at the right stage. Sci Transl Med 3, $111 \mathrm{~cm} 33$.

[71] Dubois B, Hampel H, Feldman HH, Scheltens P, Aisen P, Andrieu S, Bakardjian H, Benali H, Bertram L, Blennow K, Broich K, Cavedo E, Crutch S, Dartigues J-F, Duyckaerts C, Epelbaum S, Frisoni GB, Gauthier S, Genthon R, Gouw AA, Habert M-O, Holtzman DM, Kivipelto M, Lista S, Molinuevo J-L, O'Bryant SE, Rabinovici GD, Rowe C, Salloway S, Schneider LS, Sperling R, Teichmann M, Carrillo MC, Cummings J, Jack CR Jr (2017) Preclinical Alzheimer's disease: Definition, natural history, and diagnostic criteria. Alzheimers Dement 12, 292-323.

[72] Solomon A, Mangialasche F, Richard E, Andrieu S, Bennett DA, Breteler M, Fratiglioni L, Hooshmand B, Khachaturian AS, Schneider LS, Skoog I, Kivipelto M (2014) Advances in the prevention of Alzheimer's disease and dementia. J Intern Med 275, 229-250.

[73] Schneider LS (2012) Recruitment methods for United States Alzheimer disease prevention trials. J Nutr Health Aging 16, 331-335.

[74] DeKosky ST, Williamson JD, Fitzpatrick AL, Kronmal RA, Ives DG, Saxton JA, Lopez OL, Burke G, Carlson MC, Fried LP, Kuller LH, Robbins JA, Tracy RP, Woolard NF, Dunn L, Snitz BE, Nahin RL, Furberg CD (2008) Ginkgo biloba for prevention of dementia: A randomized controlled trial. JAMA 300, 2253-2262.

[75] Andrieu S, Ousset P-J, Coley N, Ouzid M, MathiexFortunet H, Vellas B (2008) GuidAge study: A 5-year double blind, randomised trial of EGb 761 for the prevention of Alzheimer's disease in elderly subjects with memory complaints. i. rationale, design and baseline data. Curr Alzheimer Res 5, 406-415.

[76] Vellas B, Carrie I, Gillette-Guyonnet S, Touchon J, Dantoine T, Dartigues JF, Cuffi MN, Bordes S, Gasnier Y, Robert P, Bories L, Rouaud O, Desclaux F, Sudres K, Bonnefoy M, Pesce A, Dufouil C, Lehericy S, Chupin M, Mangin JF, Payoux P, Adel D, Legrand P, Catheline D, Kanony C, Zaim M, Molinier L, Costa N, Delrieu J, Voisin T, Faisant C, Lala F, Nourhashemi F, Rolland Y, Van Kan GA, Dupuy C, Cantet C, Cestac P, Belleville S, Willis S, Cesari M, Weiner MW, Soto ME, Ousset PJ, Andrieu S (2014) MAPT study: A multidomain approach for preventing Alzheimer's disease: Design and baseline data. J Prev Alzheimers Dis 1, 13-22.

[77] Biomarker Qualification for Risk of Mild Cognitive Impairment (MCI) Due to Alzheimer's Disease (AD) and Safety and Efficacy Evaluation of Pioglitazone in Delaying Its Onset - Full Text View - ClinicalTrials.gov: https://clinicaltrials.gov/ct2/show/NCT01931566

[78] Ngandu T, Lehtisalo J, Solomon A, Levalahti E, Ahtiluoto S, Antikainen R, Backman L, Hanninen T, Jula A, Laatikainen T, Lindstrom J, Mangialasche F, Paajanen T, Pajala S, Peltonen M, Rauramaa R, Stigsdotter-Neely A, Strandberg T, 
Tuomilehto J, Soininen H, Kivipelto M (2015) A 2 year multidomain intervention of diet, exercise, cognitive training, and vascular risk monitoring versus control to prevent cognitive decline in at-risk elderly people (FINGER): A randomised controlled trial. Lancet $\mathbf{3 8 5}, 2255-2263$.

[79] Peters KR, Lynn Beattie B, Feldman HH, Illes J (2013) A conceptual framework and ethics analysis for prevention trials of Alzheimer disease. Prog Neurobiol 110, 114-123.

[80] Chen Y, Denny KG, Harvey D, Farias ST, Mungas D, DeCarli C, Beckett L (2017) Progression from normal cognition to mild cognitive impairment in a diverse clinicbased and community-based elderly cohort. Alzheimers Dement 13, 399-405.

[81] Ritchie CW, Molinuevo JL, Truyen L, Satlin A, Van der Geyten S, Lovestone S (2016) Development of interventions for the secondary prevention of Alzheimer's dementia: The European Prevention of Alzheimer's Dementia (EPAD) project. Lancet Psychiatry 3, 179-186. 